\title{
Mechanisms of genuine humic acid evolution and its dynamic interaction with methane production in anaerobic digestion processes
}

\author{
Xiqing Wang ${ }^{1}$, Atif Muhmood ${ }^{1}$, Tao Lyu $^{2}$, Renjie Dong ${ }^{1}$, Hongtao Liu ${ }^{3}$, Shubiao Wu ${ }^{* 4}$ \\ ${ }^{1}$ Key Laboratory of Clean Utilization Technology for Renewable Energy, Ministry of Agriculture, College of Engineering, \\ China Agricultural University, 100083, Beijing, P. R. China \\ ${ }^{2}$ Cranfield Water Science Institute, Cranfield University, College Road, Cranfield, Bedfordshire, MK43 OAL, UK \\ ${ }^{3}$ Institute of Geographic Science and Natural Resources Research, Chinese Academy of Sciences, Beijing 100101, China \\ ${ }^{4}$ Aarhus Institute of Advanced Studies, Aarhus University, DK-8000 Aarhus C, Denmark \\ *Correspondence. E-mail: wushubiao@gmail.com
}

\section{Abstract}

Humic acid (HA), a byproduct formed during the biological conversion of organic matter into biogas in the anaerobic digestion (AD) process, contains complex structures and redox functions. However, the evolution mechanism of $\mathrm{HA}$ and its interaction with $\mathrm{CH}_{4}$ production during the AD process have not been fully explored, particularly with respect to various substrates and temperature conditions. In this study, we investigated the evolutionary dynamics of the structure and function of genuine HA that naturally formed in the $A D$ processes of chicken manure and corn stover under mesophilic $\left(37^{\circ} \mathrm{C}\right)$ and thermophilic $\left(55^{\circ} \mathrm{C}\right)$ conditions. The results demonstrated that the $\mathrm{HA}$ evolution mechanisms in $A D$ of chicken manure and corn stover have different pathways. The $A D$ of core stover showed higher degree of aromaticity $(41.2-66.7 \%$ and $45.3-68.4 \%$ for mesophilic and thermophilic respectively) and humification index (1.5-4.2 and 2.8-4.5 for mesophilic and thermophilic respectively) than those $(28.3-45.3 \%$ and $30.2-54.5 \%$ of aromaticity and 0.6-1.2 and 1.3-3.7 of humification index) in AD of chicken manure. The 
results from HSQC NMR spectroscopy and 2D-COS-FTIR spectroscopy demonstrated an accelerating effect of the higher temperature on the evolution of HA through humification. Moreover, the concurrent decomposition and re-polymerization of HA during both $\mathrm{AD}$ processes, resulting in positive and negative effects on $\mathrm{CH}_{4}$ production in the fast and slow $\mathrm{CH}_{4}$ production stages, respectively. The dynamic interaction was due to variations in the electron transferring ability and structure of the formed HA. The results could not only advance our understanding of the mechanisms of HA evolution and its interaction with the performance of $A D$ process, but also support further research toward improving $A D$ performance by regulating $H A$ formation and transformation.

Keywords: Biogas production; humic substances; humification; redox capacity; repolymerization

\section{Introduction}

Anaerobic digestion (AD) is a widely implemented biological technology in agriculture that not only offers an appropriate treatment of various agricultural residuals but also provides essential, clean, and affordable renewable energy to society (Maynaud et al., 2017; Somers et al., 2018). In AD processes, organic matter is degraded via a series of microbially mediated reactions initiated by hydrolysis of organic macromolecules into soluble organic units, followed by the production of $\mathrm{CH}_{4}$ and $\mathrm{CO}_{2}$ by degrading these

43 soluble compounds via the pathways of acidogenesis, acetogenesis, and methanogenesis (Martins das Neves et al., 2009; Sepehr et al., 2018). The occurrence of these biological degradations leads to the production of a great variety of organic 
components such as polyphenols and polysaccharides that can form recalcitrant macromolecular organics, such as humic substances (HS), through the re-polymerization process (Sánchez-Monedero et al., 1999; Baddi et al., 2009). Thus, humic acid (HA), as a major fraction of HS has shown to be a bulk component and usually accounts for $10-20 \%$ of the total solids in the anaerobic digesters, with $5-10 \mathrm{~g} / \mathrm{L}$ of content, which varies depending on the feeding materials and operational conditions (Yap et al., 2018; Guo et al., 2019).

The HA has been deemed a complicated macromolecule that contains many active functional groups, such as carboxylic acid, phenolic, and quinone types (Said-Pullicino et al., 2016; Nie et al., 2018). Recently, the impact of HA on AD performance has increasingly attracted the attention of scientists, and some laboratory experiments have been conducted to study the interaction through the addition of commercial HA or HA analogs in the AD process (Yap et al., 2017; Li et al., 2019a; Bai et al., 2019). The main mechanistic hypothesis concluded from these investigations on the inhibiting impact of $\mathrm{HA}$ on the AD performance is due to the binding of active functional groups in HA to the active sites of relevant key enzymes (such as hydrolytic enzymes), thereby preventing their access to substrates (Yap et al., 2017). Moreover, HA has recently been reported to serve as terminal electron acceptors during microbial respiration and function as electron shuttles driving the anaerobic oxidation of methane (Bai et al., 2019) and accelerating the consumption of organic substances during the AD process (Wang et al., 2019). Although a few recent studies have observed the inhibiting effect of commercial $\mathrm{HA}$ on the $\mathrm{AD}$ process, which is indicated by the reduced $\mathrm{CH}_{4}$ production, the conclusions may hardly be applied to understand the impact of genuine HA that naturally forms in 
the AD process (Yap et al., 2017 and 2018; Li et al., 2019b). The structure and function of the commercial $\mathrm{HA}$ are relatively consistent during the whole $\mathrm{AD}$ experiment, which is insufficient to be representative of the naturally formed HA with dynamic abundance, active functional groups, and electron transferring abilities in different phases of the AD process (Tang et al., 2018; Ma et al., 2019). Therefore, in-situ monitoring of naturally formed HA with dynamic characteristics is crucial for re-evaluating and understanding the underlying mechanisms of the effect of HA on AD performance.

The process of HA formation, also called humification, involves various microorganismdominated biological and biochemical processes (Hayes et al., 2009; Mylotte et al., 2016). To date, different hypotheses, including lignin-protein theory, polyphenol theory, and sugar-amine condensation theory, have been used to explain the humification (Tan, 2014; Wu et al., 2017; Gao et al., 2019). Generally, the complex organic compounds containing HA precursors could first be decomposed into small-molecule organics and then transformed into recalcitrant macromolecular organic products through the repolymerization to form HA under relevant microorganism functions (Gao et al., 2019). For example, Tang et al. (2020) found the original HA in extracellular polymeric substances could be degraded and modified, and HA with abundant aromatic sites may also bridge protein condensation to regenerate HA during sewage sludge AD process (Tang et al., 2020). Moreover, during humification, precursors from different sources (feeding materials in the AD process) would enable the formation of HA with different molecular compositions, structures, and functionalities due to the different elemental compositions and properties of raw materials (Sale et al., 2015; He et al., 2018). Likewise, the fermentation temperature could also affect the humification pathway and the 
stability of the formed HA (Jiang et al., 2015; Onwosi et al., 2017). Nevertheless, current knowledge about HA formation mechanisms is largely derived from research on composting, which is primarily led by a group of aerobic microorganisms (Gao et al., 2019; He et al., 2015). Although the phenomenon of HA formation has been observed insufficient. 


\section{Materials and methods}

\subsection{Setup of the batch AD experiments}

Batch AD experiments were conducted in this study using $120 \mathrm{~mL}$ serum bottles with a working volume of $60 \mathrm{~mL}$. The commonly used $A D$ feeding materials (chicken manure and corn stover) were fermented under mesophilic $\left(37^{\circ} \mathrm{C}\right)$ and thermophilic $\left(55^{\circ} \mathrm{C}\right)$ conditions for 40 days. The chicken manure was collected from the Deqingyuan biogas plant, which is located in the suburbs of Beijing, China. The total solid (TS) and volatile solid (VS) contents of the chicken manure were $10.01 \%$ and $7.88 \%$, respectively (Table 1). The corn stover was obtained from the University farm of China Agricultural University in Beijing, China, and had TS and VS values of $85.90 \%$ and $73.12 \%$, respectively (Table 1). Likewise, the sludge from long-term laboratory-scale mesophilic $\left(37^{\circ} \mathrm{C}\right)$ digesters fed with chicken manure (TS of $4.98 \%$ and VS of $2.23 \%$ ) and corn stover (TS of $6.75 \%$ and VS of $3.45 \%$ ) were used as the corresponding inoculum for the AD of chicken manure and corn stover, respectively. Moreover, the sludge from long-term laboratoryscale mesophilic $\left(55^{\circ} \mathrm{C}\right.$ ) digesters fed with chicken manure (TS of $5.01 \%$ and VS of $1.98 \%$ ) and corn stover (TS of $6.52 \%$ and VS of 3.05\%) were used as the corresponding inoculum for the AD of chicken manure and corn stover, respectively. The organic matter ratio of the substrate and the inoculum was 1:2 (Guo et al., 2018). The experimental AD bottles were marked and placed in a temperature-controlled incubator (RZH-380A, artificial climate chamber, China), and each treatment was performed in triplicate. Four replicate bottles filled with inoculum alone were used as blanks in each treatment group under the same experimental conditions. Further details on the setup of the batch experiments can be found in Text S1 of the Supporting Information. 
139 Characteristic of chicken manure, corn stover and inoculum sludge

\begin{tabular}{ccccc}
\hline Parameters & $\mathrm{pH}$ & $\mathrm{TS}(\%)$ & $\mathrm{VS}(\%)$ & $\mathrm{VS} / \mathrm{TS}(\%)$ \\
\hline $\begin{array}{c}\text { Chicken manure } \\
\text { Corn stover }\end{array}$ & $7.52 \pm 0.20$ & $10.01 \pm 0.50$ & $7.88 \pm 0.41$ & $78.72 \pm 0.32$ \\
$\begin{array}{c}\text { Inoculum sludge } \\
\left.\text { (Chicken manure, } 37^{\circ} \mathrm{C}\right)\end{array}$ & $7.89 \pm 0.09$ & $4.98 \pm 0.25$ & $2.23 \pm 0.17$ & $44.78 \pm 0.43$ \\
$\begin{array}{c}\text { Inoculum sludge } \\
\left.\text { (Chicken manure, } 55^{\circ} \mathrm{C}\right)\end{array}$ & $7.95 \pm 0.12$ & $5.01 \pm 0.31$ & $1.98 \pm 0.26$ & $39.52 \pm 0.52$ \\
$\begin{array}{c}\text { Inoculum sludge } \\
\left.\text { (Corn stover, } 37^{\circ} \mathrm{C}\right)\end{array}$ & $7.22 \pm 0.11$ & $6.75 \pm 0.18$ & $3.45 \pm 0.14$ & $51.11 \pm 0.29$ \\
$\begin{array}{c}\text { Inoculum sludge } \\
\text { (Corn stover, } 55^{\circ} \mathrm{C} \text { ) }\end{array}$ & $7.19 \pm 0.13$ & $6.52 \pm 0.16$ & $3.05 \pm 0.11$ & $46.78 \pm 0.12$ \\
\hline
\end{tabular}

140 Daily biogas production was measured using a water displacement manometer (GF-500,

141 KIMO, France). The biogas composition was analysed via gas chromatography with a

142 thermal conductivity detector (SP 2100, BFRL, China). The Gompertz model was used to

143 fit the measured $\mathrm{CH}_{4}$ yield and identify two $\mathrm{CH}_{4}$ production stages (fast and slow) (Zhang

144 et al., 2014). The digested slurry was regularly sampled every five days and then

145 immediately analysed in the laboratory for physicochemical properties, including $\mathrm{pH}$,

146 total solids, and volatile solids (VS), according to the standard methods (APHA, 1998;

147 Luo et al., 2018). Further details on the analysis of these physicochemical properties are 148 described in Text S2-1 of the Supporting Information.

$149 \quad 2.2$ Characteristics of fluorescent components

150 The excitation-emission matrix (EEM) spectra were recorded using a fluorescence

151 spectrophotometer (Aqualog, HORIBA) to analyze the evolution of the OM in the $A D$ process. The sampled digested slurry was first diluted with distilled water 50 times 
153 before the fluorescence spectra analysis. The emission wavelengths $(250-550 \mathrm{~nm})$ and

154 excitation wavelengths (250-600 nm) over the range were observed in 5 and $3 \mathrm{~nm}$

155 increments, respectively. The Rayleigh and Raman scattering of the EEM data were 156 calibrated using the method described by Bahram et al. (2006). Finally, parallel factor 157 (PARAFAC) analysis was carried out using MATLAB R2018a (MathWorks, USA) with the DOMFluor Toolbox. Moreover, the fluorescence parameters, including biological index $(B I X)$ and humification index (HIX), were obtained using the data collected through fluorescence spectroscopy. Further detailed information on the EEM and PARAFAC analyses are described in Text S2-2 of the Supporting Information.

\subsection{Extraction of humic acid in the sampled digested slurry}

The extraction and purification of the HA fraction in the sampled digested slurry were conducted according to the standard method recommended by the International Humic Substances Society (Swift et al., 1996). Briefly, the sampled digested slurry was first shaken (200 rpm, $24 \mathrm{~h}$ ) with a mixed solution of $0.1 \mathrm{M} \mathrm{Na}_{4} \mathrm{P}_{2} \mathrm{O}_{7}$ and $0.1 \mathrm{M} \mathrm{NaOH}$ at a $1: 10(w: v)$ ratio at room temperature. The supernatant was filtered through a $0.45 \mu \mathrm{m}$ Millipore membrane after $20 \mathrm{~min}$ of centrifugation (11,000 rpm). The procedure was repeated three times, and the supernatant was filtered through a $0.45 \mu \mathrm{m}$ Millipore membrane, acidified with $6 \mathrm{M} \mathrm{HCl}$ to $\mathrm{pH} 1$ and left overnight. The precipitate was separated from the liquid phase by centrifugation ( $5000 \mathrm{rpm}, 10 \mathrm{~min}$ ), suspended in 100 $\mathrm{ml} \mathrm{NaOH}$ and $\mathrm{Na}_{4} \mathrm{P}_{2} \mathrm{O}_{7}$ mixed solution and shaken overnight. The solution was then centrifuged (5000 rpm, $10 \mathrm{~min}$ ), and the liquid phase was acidified with $0.1 \mathrm{M} \mathrm{HCl} / 0.3$ $\mathrm{M}$ hydrogen fluoride to $\mathrm{pH} \mathrm{1,} \mathrm{left} \mathrm{to} \mathrm{stand} \mathrm{overnight} \mathrm{and} \mathrm{centrifuged.} \mathrm{The} \mathrm{precipitated}$ 
was dialyzed against distilled water until $\mathrm{Cl}^{-}$could no longer be detected (Zhao et al., 2020).

\subsection{Humic acid characterization}

The carbon $(C)$, hydrogen $(H)$, and nitrogen $(N)$ contents of HA were analysed using an elemental analyzer (Vario EL cube, Germany); the $\mathrm{H} / \mathrm{C}, \mathrm{C} / \mathrm{N}$, and $\mathrm{C} / \mathrm{O}$ ratios were calculated to analyse the elemental characteristics of HAs. The parameter-specific UV absorbance at $254 \mathrm{~nm}$ and $280 \mathrm{~nm}$ was measured using a UV-vis spectrophotometer (Shimadzu, UV-2600). SUVA254 is used to characterize the relative aromaticity of HA (Weishaar et al., 2003); similarly, SUVA280 is suitable for tracking the $\pi-\pi^{*}$ electron transitions in the UV range $(270-280 \mathrm{~nm})$ for phenolic substances, aniline derivatives, benzoic acids, polyenes, and polycyclic aromatic hydrocarbons (Tang et al., 2018). The content changes in the aliphatic and aromatic components of HA were complemented by one-bond ${ }^{1} \mathrm{H}-{ }^{13} \mathrm{C}$ HSQC NMR spectra using an Avance III $600 \mathrm{MHz}$ spectrometer (Bruker, The Woodlands, TX). Detailed information on this method is described in Text S2-3 (Supporting Information).

FTIR spectra, a mainstream tool for determining functional groups and analyzing the structural composition of sampled HA, was utilized in this study using a Nicolet IS10 FTIR spectrophotometer from 4,000 to $400 \mathrm{~cm}^{-1}$ (Zhou et al., 2014). Then, two-dimensional correlation spectra (2D-COS) were used to improve the spectral resolution and characterize the changing degree and order of different functional groups under different conditions. The interpretation of the synchronous and asynchronous plots obtained from 2D-COS was mainly based on Noda's rule (Noda and Ozaki, 2004); additional details are provided in Text S2-4 (Supporting Information). 
198 To further investigate the qualitative characterization of the molecular composition of

199 the extracted HA in this study, pyrolysis-gas chromatography/mass spectroscopy (Py-

$200 \mathrm{GC} / \mathrm{MS}$ ) analysis was performed on a Pyroprobe pyrolyzer (6890 GC/5973 MSD, Agilent,

201 USA). Py-GC/MS analysis for each sample was repeated twice and found to have proper

202 repeatability. The compounds obtained through GC/MS were identified via the NIST

203 database by closest match in the NIST MS Search 2.3 using identity-type searching. The

204 threshold for the match factor was 85\% (Shahbeig and Nosrati, 2020). The detailed

205 information can be found in Text S2-5 (Supporting Information).

206 To explore the potential of HA to serve as terminal electron acceptors during microbial

207 respiration and function as electron shuttles to drive the redox bioconversion of organic

208 molecules in the AD process (Tan et al., 2017), the electron transfer capacities (ETCs),

209 including the electron-donating capacity (EDC) and electron-accepting capacity (EAC) of

$210 \mathrm{HA}$, were measured using mediated electrochemical reduction and oxidation methods

211 (Wang et al., 2020). Detailed information on this method is described in Text S2-6

212 (Supporting Information).

\section{$213 \quad 2.5$ Principal component analysis and structural equation modelling}

214 PCA was used to identify different $A D$ performance patterns during the entire $A D$

215 process at different temperatures. The components used for PCA included $\mathrm{CH}_{4}$

216 production, $\mathrm{HIX}$, and all the OM components during the AD process of chicken manure

217 and corn stover. A cluster analysis was performed according to the eigenvalues of each

218 component, and the results were used to group similar patterns in the PCA coordinates.

219 SEM was then used to clarify the direct and indirect relationships between HA formation

220 and its impact on the AD process (Gao et al., 2019). Before SEM analysis, auto-regressive 
221 correlation structures were used to identify potential autocorrelations in the IBM SPSS

222 AMOS 23.0 data. Then, we established an a priori model according to our current

223 knowledge of $\mathrm{HA}$ formation and interaction with $\mathrm{CH}_{4}$ production, and the data matrix

224 was fitted to the model using the maximum-likelihood estimation method with AMOS

22523.0 software (SPSS Inc., Chicago, IL). The $\chi$-square test in SPSS software was used to

226 verify the quality of the fit. Finally, we determined the structural changes of HA and the

227 factors affecting $\mathrm{CH}_{4}$ production, and we calculated the weight of each factor's influence 228 on $\mathrm{CH}_{4}$ production.

\section{3. Results and discussion}

$230 \quad 3.1$ Organic matter transformation in the AD process

231 During the mesophilic AD process, approximately $12 \%$ and $2 \%$ of the cumulative $\mathrm{CH}_{4}$

232 yields of chicken manure and corn stover ( $254 \pm 7$ and $227 \pm 6 \mathrm{~mL} \mathrm{gVS}^{-1}$, respectively) were 233 lower than the yields obtained in the thermophilic AD process $(327 \pm 9$ and $321 \pm 10 \mathrm{~mL}$ 234 gVS $^{-1}$, respectively) (Fig. $1 \mathrm{a}$ and b). $\mathrm{CH}_{4}$ generation in $\mathrm{AD}$ was mainly achieved by the 235 microbially mediated transformation of the organics (Martins das Neves et al., 2009; 236 Sepehr et al., 2018), and higher temperature fermentation conditions had the 237 advantage of increasing the hydrolysis rate of organics toward increased $\mathrm{CH}_{4}$ production 238 (Croce et al., 2016). These results were also supported by the higher degradation of VS 239 in the thermophilic AD process (39.6\% and 39.6\% for chicken manure and corn stover, 240 respectively) than those in the mesophilic $A D$ process $(38.3 \%$ and $34.8 \%$ for chicken 241 manure and corn stover, respectively) (Table S1 and S2). Along with the AD process, the $242 \mathrm{CH}_{4}$ production rate is strongly replied on the microbial degradation rate of the organic 243 matter. Based on this concept, the Gompertz model, as a classical kinetic model, has 
244 been developed to simulate the $\mathrm{CH}_{4}$ production and distinguish different stages of the

$245 \mathrm{CH}_{4}$ production rates in AD process (Zhang et al., 2014). According to the determined

246 daily $\mathrm{CH}_{4}$ generation (Fig. S1) and the theoretical Gompertz model, the transmission of

247 fast (stage I, Fig. 1) and slow (stage II, Fig. 1) $\mathrm{CH}_{4}$ production stages were identified for

248 the AD of chicken manure (day 10) and corn stover (day 18) without differences between

249 the mesophilic and thermophilic conditions.

250 PARAFAC analyses based on the EEM fluorescence spectra were used to illustrate the 251 transformations of $\mathrm{OM}$ in the AD process (Fig. 2a-h). Five fluorescent components were 252 identified (Table S3), comprising two humic-like compounds (C1 and C3), one fulvic-like 253 compound (C2), protein-like and tyrosine-like substances (C4), and tryptophan-like substances (C5) (He et al., 2015; Wang et al., 2020). Among them, the abundance of 255 protein-like components decreased with an increase in the humic-like components during the AD process for both materials (Fig. S2). Along with the transformation of OM, 257 the content of HA decreased from $8.4 \pm 0.9$ to $4.6 \pm 0.6 \mathrm{~g} \mathrm{~L}^{-1}$ in the fast $\mathrm{CH}_{4}$ production stage and then gradually increased to $7.7 \pm 0.8 \mathrm{~g} \mathrm{~L}^{-1}$ during the slow $\mathrm{CH}_{4}$ production conditions, the content of HA continuously decreased from the initial value of $6.8 \pm 0.7$ to $4.1 \pm 0.4 \mathrm{~g} \mathrm{~L}^{-1}$ in the fast $\mathrm{CH}_{4}$ production stage and maintained a similar level until the end of the experiment. The dynamics of the HA content in the AD of corn stover showed a different tendency (Fig. 1d). The HA content increased from 4.5-4.9 to 7.1-7.5 $\mathrm{g} \mathrm{L}^{-1}$ in

264 the first five days and then decreased to 3.9-4.1. $\mathrm{g} \mathrm{L}^{-1}$ in the fast $\mathrm{CH}_{4}$ production stage under both temperature conditions. In the slow $\mathrm{CH}_{4}$ production stage, the $\mathrm{HA}$ content gradually increased to $4.6-5.2 . \mathrm{g} \mathrm{L}^{-1}$ by day 40. 
267 Integrating the dynamics of HA content during the AD process (Fig. 1c and d) indicated 268 the concurrent decomposition and formation of HA during the AD process. It was 269 reported that the initial HA content in the feeding material and/or inoculum would first 270 degrade in the fast $\mathrm{CH}_{4}$ production stage along with the biodegradation of the organics 271 (Tang et al., 2018); however, in the following slow $\mathrm{CH}_{4}$ generation stage, essential 272 precursors to the formation of HA, such as polyphenols, carboxylic acids, and amino 273 acids via the transformation of the $\mathrm{OM}$, could be generated and lead the repolymerization of HA (Gao et al., 2019). Notably, the fast HA content increase in the early stage for corn stover (Fig. 1d) may be attributed to the abundance of fiber276 structural components (e.g., lignin), which provides more stable phenolic compounds 277 required as starting materials for humification processes (Lopez et al., 2002). Moreover, 278 significantly lower HA contents were quantified under the thermophilic conditions than 279 in the mesophilic conditions, indicating the stimulating effect of higher temperatures on 280 HA degradation (Putranto et al., 2017). This can be attributed to the faster microbial 281 degradation of polysaccharides, proteins, and fats to $\mathrm{CH}_{4}$ instead of re-polymerization 282 to HA (Jiang et al., 2015; Onwosi et al., 2017), which results in higher biogas production 283 under the thermophilic AD process (Fig. 1a and b). 

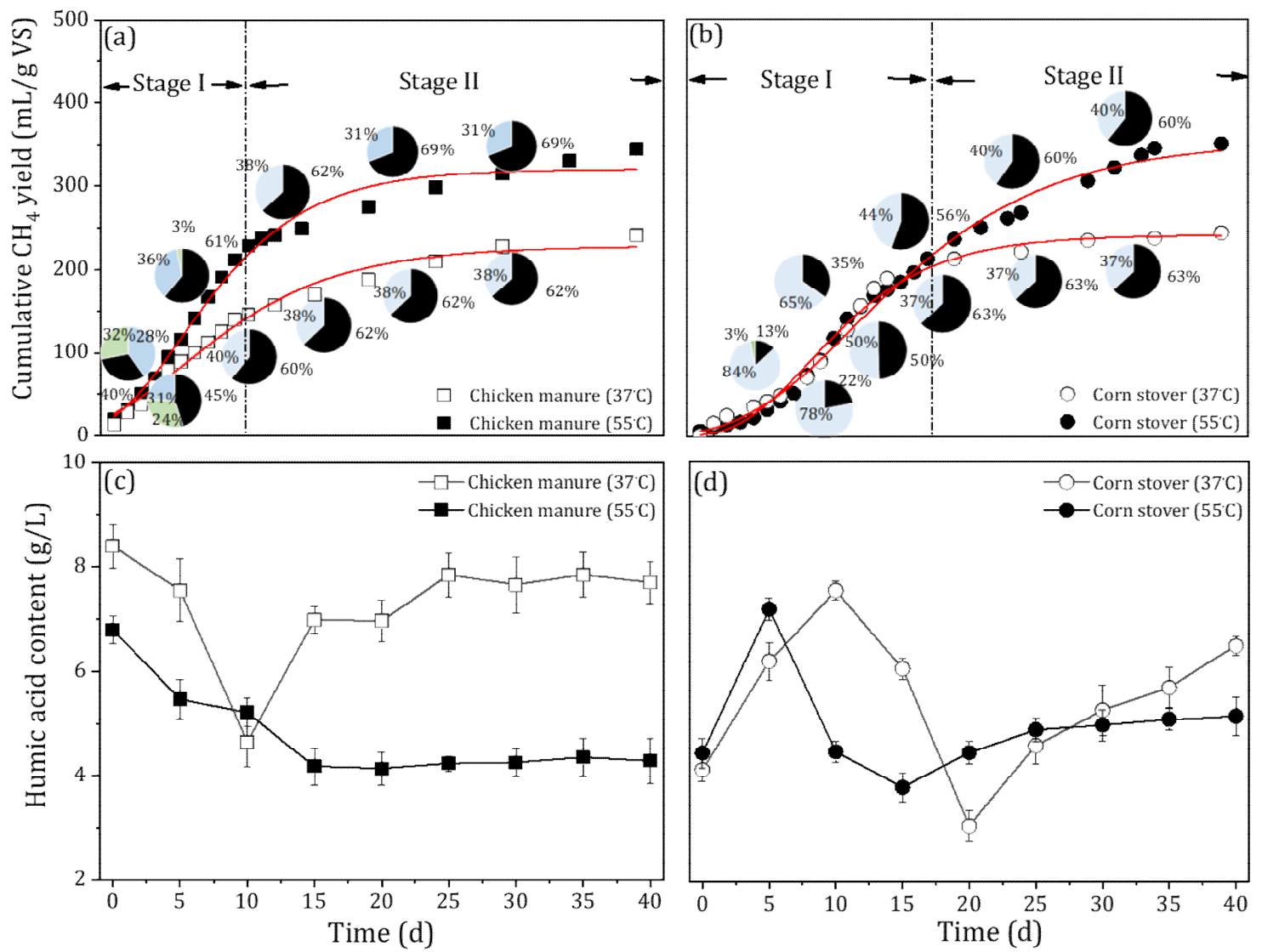

Fig. 1. The cumulative methane produced and humic acid content during chicken manure $(a, c)$ and corn stover (b, d) anaerobic digestion at different temperatures. The black, blue, and green areas in the pie chart represent methane, carbon dioxide, and nitrogen content, respectively (Stage I: fast methane production stage; Stage II: Slow methane production stage).

\subsection{Characterization of the humification process}

290 Target fluorescence indexes, including biological index (BIX) and humification index

291 (HIX), were calculated to evaluate the characteristics of the humification process for HA

292 formation in different AD processes (Fig. 2i-I). BIX is commonly used to evaluate the

293 autochthonous biological activity of the formed HA, where a high BIX value corresponds

294 to the presence of freshly produced HA (Tedetti et al., 2011; He et al., 2015). In this study,

295 the declining trend of the BIX value in both AD processes of chicken manure (from 1.01-

2961.06 to $0.65-0.69$ ) and corn stover (from 0.95-1.03 to $0.81-0.82$ ) represented the aging process of the freshly formed HA to the humified structure. Besides, HIX is a general 
298 indicator of the degree of humification of HA and is positively related to the complexity

299 of the structure (Huguest et al., 2009). The HIX values of the formed HA in the

300 thermophilic AD process (1.26-3.68) were significantly higher than those in the

301 mesophilic AD of chicken manure (0.58-1.18), indicating the positive effect of higher

302 temperature on the HA humification process (Fig. 1c) (Guo et al., 2019).

303 Although the temperature effect on HIX in the AD of corn stover was not significant, the

304 continually increased values (from 1.49-2.77 to 4.19-4.52) indicated the strengthened

305 humification process during the AD process under both temperature conditions (Fig. $2 \mathrm{k}$

306 and I). The influence of temperature on HIX formation is different for distinct substrates

307 may due to the composition of the corn stover has abundant lignocellulosic compounds

308 compared with chicken manure (Gao et al., 2019). To confirm these changes in the

309 structure of HA, the levels of the aromaticity of HA in different AD processes were

310 further determined by HSQC NMR spectroscopy (Fig. S3). Similarly, the results showed

311 a higher increase in the aromaticity (30.2-68.4\%) in the HA formed in the thermophilic

312 AD process than those (28.3-66.7\%) in the mesophilic AD process (Table S4), which

313 agreed with the changes in BIX and HIX. The degradation of superficial labile aliphatics

314 in HA was improved under thermophilic conditions, which might be the reason for the

315 increase in the degree of humification during the thermophilic AD process (Tang et al., 316 2018). 

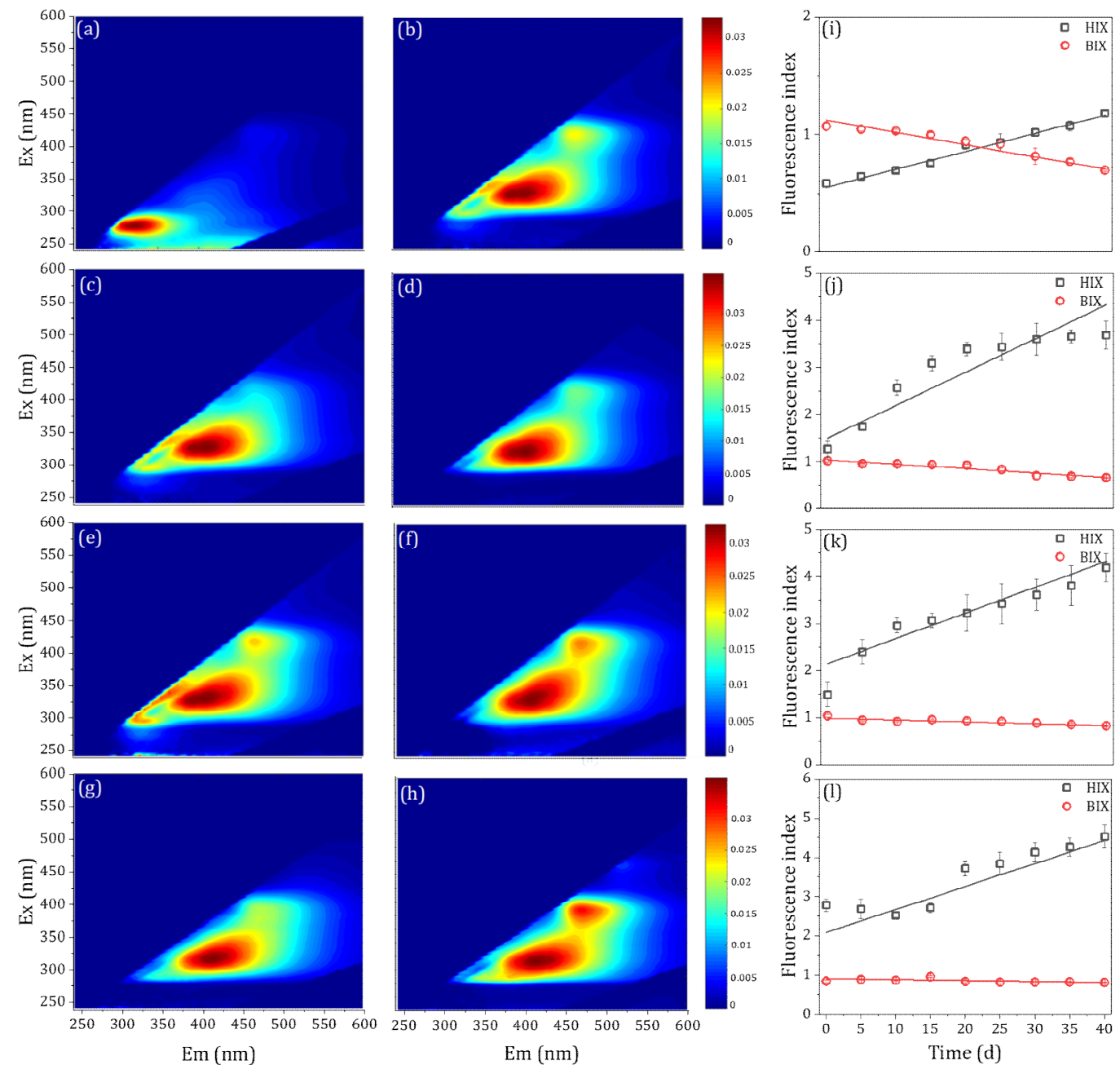

$$
\operatorname{Em}(\mathrm{nm})
$$

Time (d)

318 Fig. 2. Excitation-emission matrix fluorescence spectra of OM, and the humification index (HIX) 319 and biological index (BIX) evolution during the mesophilic and thermophilic anaerobic digestion of chicken manure and corn stover. $(a, b)$ mesophilic anaerobic digestion of chicken manure at 0 and 40 days; $(c, d)$ thermophilic anaerobic digestion of chicken manure at 0 and 40 days; $(e, f)$ mesophilic anaerobic digestion of corn stover at 0 and 40 days; $(\mathrm{g}, \mathrm{h})$ thermophilic anaerobic digestion of corn stover at 0 and 40 days; $(\mathrm{i}, \mathrm{j}) \mathrm{HIX}$ and BIX from the mesophilic and thermophilic anaerobic digestion of chicken manure, respectively; $(k, I)$ HIX and BIX from the mesophilic and thermophilic anaerobic digestion of corn stover, respectively.

\subsection{Variation in the functional groups of HA}

327 Due to the complex structure of HA, the simple FTIR image (Fig. S4) cannot identify the

328 changes in the functional groups based on the obtained infrared absorption spectra

329 (Gao et al., 2019). Thus, a further 2D-COS analysis was applied to examine the structural 330 changes in the active functional groups of HA (Fig. 3). In the synchronous 2D-COS IR 
331 spectra, a total of six auto-peaks (at 3000, 3400, 1850,1700, 1230, and $1030 \mathrm{~cm}^{-1}$ ) and

332 six positive cross-peaks at $(1030,3000),(1700,3000),(1030,1850),(1230,1700),(1700$,

333 1850), and $(1850,3000)$ were determined, and no significant difference between the

334 mesophilic and thermophilic AD of chicken manure and corn stover was observed (Fig.

$3353 a-d)$. Notably, the intensity of the auto-peaks in the 2D-COS IR spectra for HA formed

336 from the mesophilic AD process was lower than that from the thermophilic AD process.

337 Compared with the synchronous maps, the asynchronous 2D-COS analyses of HA 338 formed from the chicken manure and corn stover AD processes showed significant 339 differences, with only cross-peaks detected (Fig. 3e-h). The asynchronous map of HA 340 produced during the AD (mesophilic and thermophilic) of chicken manure contained 341 seven negative cross-peaks at $(1030,3400),(1600,3400),(2800,3400),(1230,3400)$, 342 (1030, 1700), (1230, 1700), and (1850, 3400), and two positive cross-peaks at (1600, $3431700)$ and $(1600,2800)$. Unlike the chicken manure, three positive cross-peaks at (1600, $3443000),(1600,1700)$, and $(2800,3000)$ and five negative cross-peaks at $(1850,3000)$, $345(1230,3000),(1030,1600),(1230,1600)$, and $(3000,3400)$ were observed for HA formed 346 during the (mesophilic and thermophilic) AD of corn stover. According to Noda's rules 347 (Noda and Ozaki, 2004), the peaks reacted in the following order: $2800 \mathrm{~cm}^{-1}>3400 \mathrm{~cm}^{-1}>$ and $3400 \mathrm{~cm}^{-1}>2800 \mathrm{~cm}^{-1}>1850 \mathrm{~cm}^{-1}, 1600 \mathrm{~cm}^{-1}>1700 \mathrm{~cm}^{-1}>1230 \mathrm{~cm}^{-1}, 1030 \mathrm{~cm}^{-1}$

350 for the AD of corn stover. Therefore, the active functional groups of HA formed in the chicken manure AD process changed in the sequence of aliphatic-like substances $(C-H)>$ amides $(\mathrm{H}-\mathrm{N})$ or carbohydrates $(\mathrm{O}-\mathrm{H})>$ carboxylic acids $(\mathrm{C}=\mathrm{O})>$ polysaccharides $(\mathrm{C}=\mathrm{O})$,

353 phenol $>$ aromatic compounds, ketones $(C=C)$. The active functional groups of $\mathrm{HA}$ 
354 formed in the corn stover AD process changed in the following sequence: amides ( $\mathrm{H}-\mathrm{N})$ or carbohydrates $(\mathrm{O}-\mathrm{H})>$ aliphatic-like substances $(\mathrm{C}-\mathrm{H})>$ aromatic compounds and

356 ketones $(C=C)>$ carboxylic acids $(C=O)>$ polysaccharides $(C=0)$, phenolics ( $G$ ao et al.,
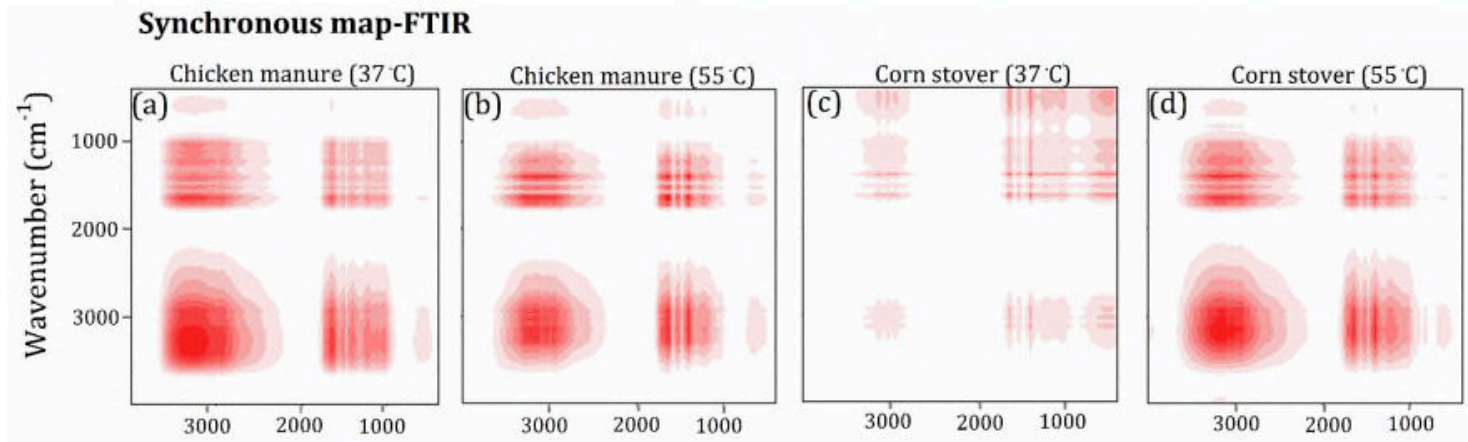

Asynchronous map-FTIR
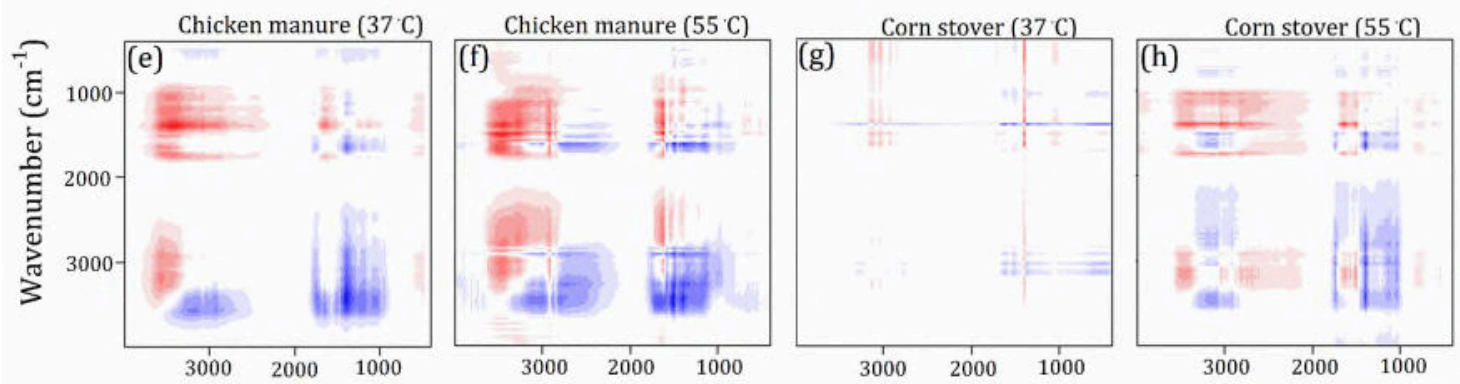

Wavenumber $\left(\mathrm{cm}^{-1}\right)$

Wavenumber $\left(\mathrm{cm}^{-1}\right)$

Wavenumber $\left(\mathrm{cm}^{-1}\right)$

Fig. 3. 2D-FTIR correlation maps generated from the $400-4000 \mathrm{~cm}^{-1}$ region of the spectra of humic acid in the anaerobic digestion of chicken manure and corn stover at different temperatures. Red and blue represent positive and negative correlations, respectively. A more intense color indicates a stronger correlation.

\subsection{Redox capability evolution of HA}

The redox capabilities of the HA transformed during the AD of chicken manure and corn stover were assessed by the ETCs of HA (Fig. S5), including the EAC and EDC. The ETCS (both EAC and EDC) of HA increased during the mesophilic and thermophilic AD of chicken manure and corn stover, which indicated the increased capability of the formed HA to influence the microbially mediated organics transformation process (Tan et al., 2017; Zhao et al., 2020). Moreover, both feeding materials and fermentation 
370 temperatures significantly affect the redox capability evolution of HA. The ETC values of

371 HA during the mesophilic AD of chicken manure $\left(671 \pm 15-1469 \pm 23 \mu \mathrm{mol} \mathrm{gHA}^{-1}\right)$ and

372 corn stover $\left(687 \pm 20-1294 \pm 25 \mu \mathrm{mol} \mathrm{gHA}^{-1}\right)$ were lower than those $(774 \pm 22-1515 \pm$

$37318 \mu \mathrm{mol} \mathrm{gHA}^{-1}$ and $1013 \pm 19-1424 \pm 21 \mu \mathrm{mol} \mathrm{gHA}^{-1}$ for chicken manure and corn stover,

374 respectively) in the thermophilic $A D$ processes. The results indicated that higher

375 temperatures could facilitate an increase in the ETCs of HA (Tan et al., 2017).

376 The ETCs of HA could contribute to the microbially mediated reactions in the AD process and influence organic transformation and $\mathrm{CH}_{4}$ generation (Bai et al., 2019). Such redox capacity heavily depends on the structure/composition of HA, such as basic elements (C, $\mathrm{N}, \mathrm{H}$, and $\mathrm{O})$ and their ratios $(\mathrm{C} / \mathrm{H}, \mathrm{C} / \mathrm{N}$, and $\mathrm{C} / \mathrm{O})$, relative aromaticity $\left(\mathrm{SUVA}_{254}\right), \pi-\pi^{*}$ electron transitions $\left(\mathrm{SUVA}_{280}\right)$, functional groups from FTIR detections, and humification degree (HIX and $\mathrm{BIX}$ ). Thus, Pearson correlation analysis was conducted to evaluate the influence of the characteristics (Table S5, S6, and S7) on the redox capacity of HA for both feeding materials under different temperature conditions (Fig. 4). During the AD of chicken manure, the ETC (EAC and EDC) was positively related to the HIX, element N, SUVA $_{254}$, SUVA $_{280}$, carbonyl group, carboxyl group, and ketone group and was negatively correlated with the $\mathrm{BIX}$ and $\mathrm{C} / \mathrm{N}$ ratio. Compared with the chicken manure AD process, was addressed, which may be due to the distinct organic sources for the AD process (He et al., 2014). 


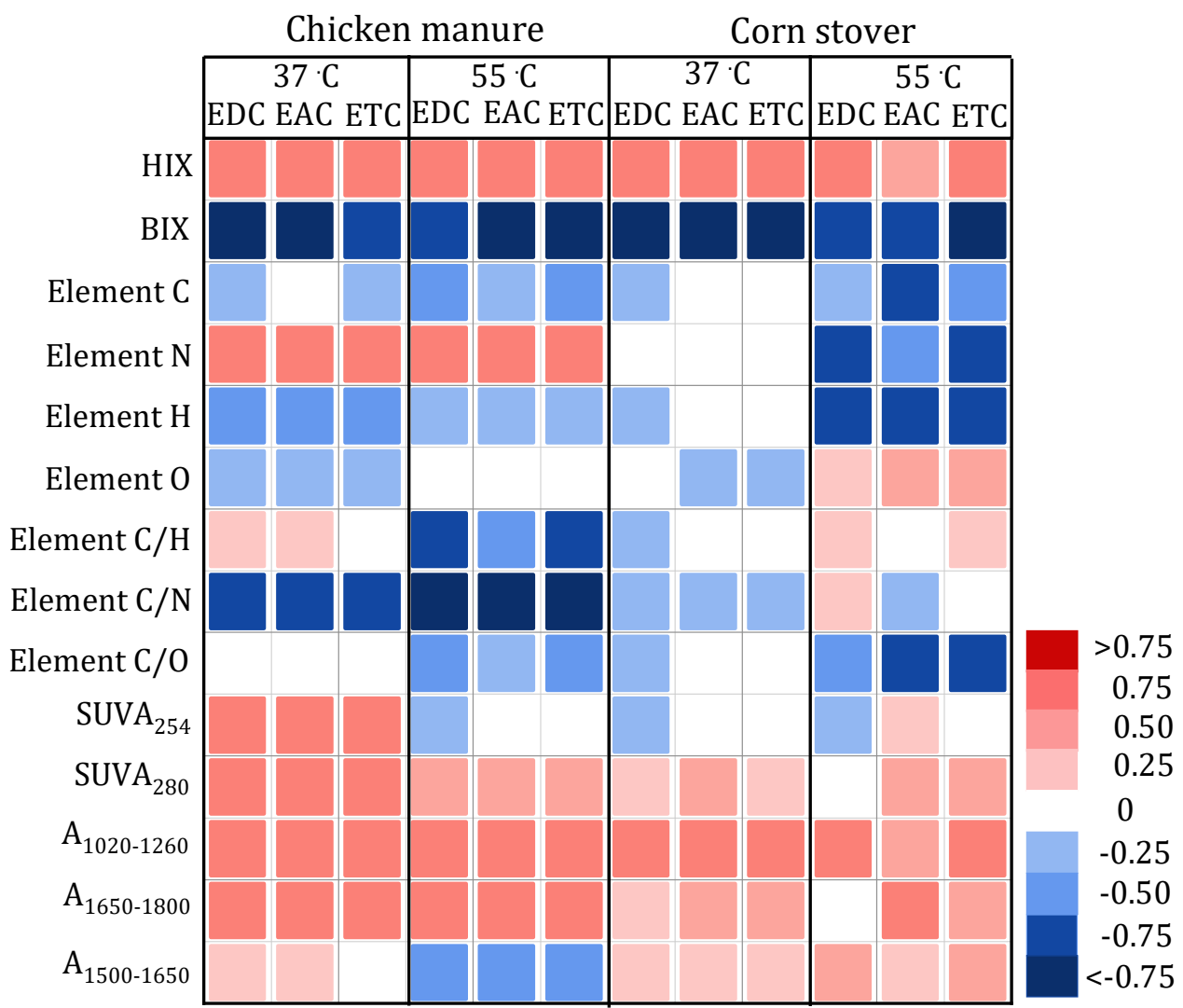

393 Fig. 4. Correlation between the chemical structure and redox properties of humic acid derived from chicken manure and corn stover anaerobic digestion. (EDC: Electron-donating capacity; EAC: Electron-accepting capacity; ETC: Electron transfer capacity; HIX: Humification index; BIX: Biological index; $A_{1020-1260}$ : The area of $1020-1260 \mathrm{~cm}^{-1}$ from FTIR represents the oxygencontaining groups (such as the carbonyl group and carboxyl group); $A_{1650-1800}$ : The area of 1650$1800 \mathrm{~cm}^{-1}$ from FTIR represents the ketone groups; $A_{1500-1650}$ : The area of $1500-1650 \mathrm{~cm}^{-1}$ from FTIR represents the $\mathrm{N}-\mathrm{H}$ and amide groups)

\subsection{Mechanisms of $\mathrm{HA}$ evolution and interaction with $\mathrm{CH}_{4}$ production}

PCA and SEM were performed to explore the potential HA evolution pathways in the AD

process with different feeding materials and temperatures (Fig. 5). Three obvious groups were identified in the PCA coordinates for both the AD of chicken manure (Fig. 5a) and corn stover (Fig. 5b). For both materials, the samples from the fast $\mathrm{CH}_{4}$ production stage were grouped without identifiable differences from the temperature conditions. The group was located in the up-left area of the coordinate, which was positively contributed by the PCA component of $\mathrm{CH}_{4}$ production and negatively contributed by the HIX. It 
indicates that the humification (HA formation) in the fast $\mathrm{CH}_{4}$ production stage does not affect $\mathrm{CH}_{4}$ production. During the slow $\mathrm{CH}_{4}$ production stage, the samples from the mesophilic and thermophilic AD processes were separated for both materials. Both groups moved towards the down-right area in the coordinates, which were positively contributed by the PCA component of $\mathrm{HIX}$ and negatively contribute by the $\mathrm{CH}_{4}$ production. The results represent the significant inhibitory effect of $\mathrm{HA}$ on $\mathrm{CH}_{4}$ generation at this stage of the AD process. Moreover, the higher factor contribution of the HIX was observed in the thermophilic AD group, which supported the negative influence of $\mathrm{HA}$ on $\mathrm{CH}_{4}$ production being stronger under thermophilic conditions than under mesophilic conditions. When looking at the HA structures, the results from PCA showed that the protein-like substances ( $\mathrm{C} 4$ and $\mathrm{C} 5$ ) were negatively correlated with humic-like substances ( $\mathrm{C} 1$ and $\mathrm{C} 3$ ) and HIX, indicating the potential contribution of the degradation of protein-like substances to HA humification (Hardie et al., 2009; Zhang et al., 2015).

SEM is an effective method to study the complex relationships between latent and observed variables (Liu et al., 2019), and it has been widely used to interpret and predict interactions in multivariate datasets (Grace, 2006; Gao et al., 2019). In this study, SEM was used to elucidate the $\mathrm{HA}$ evolution along with the organic transformation and $\mathrm{CH}_{4}$ production. The results showed a complex interaction among aliphatic compounds, aromatic compounds, amides, carboxyl acids, and HA structural characteristics (Fig. 5cf). Generally, in the AD process of chicken manure, amides and aliphatic compounds negatively affect HA structural characteristics but positively influence small molecules, such as carboxyl acids; however, in the AD process of corn stover, carbohydrates and 
431 aliphatic compounds have a significantly positive effect on amides, which indirectly

432 influence the HA structural characteristics (Fig. 5d). The contents of amide and aliphatic

433 components in $\mathrm{HA}$ have a significantly positive influence on $\mathrm{CH}_{4}$ production during the

434 fast $\mathrm{CH}_{4}$ production stage of the chicken manure and corn stover AD processes (Fig. 5c

435 and d). The higher aromatic components in HA have significantly negative impacts on

$436 \mathrm{CH}_{4}$ production during the later slow $\mathrm{CH}_{4}$ production stage (Fig. 5e and f). The results

437 indicated that the impact of $\mathrm{HA}$ on $\mathrm{AD}$ performance significantly depends on the 438 humification degree or aromaticity of HA (Yap et al., 2017; Li et al., 2019a). The aliphatic

439 compounds, amides, and carbohydrates in less humified HA can first be degraded to

440 serve as the carbon resource for microorganisms to produce $\mathrm{CH}_{4}$ (Tang et al., 2018).

441 When the HA structure becomes more complex and stable with higher aromaticity, an

442 inhibitory effect on $\mathrm{CH}_{4}$ production may appear (Li et al., 2019b). 

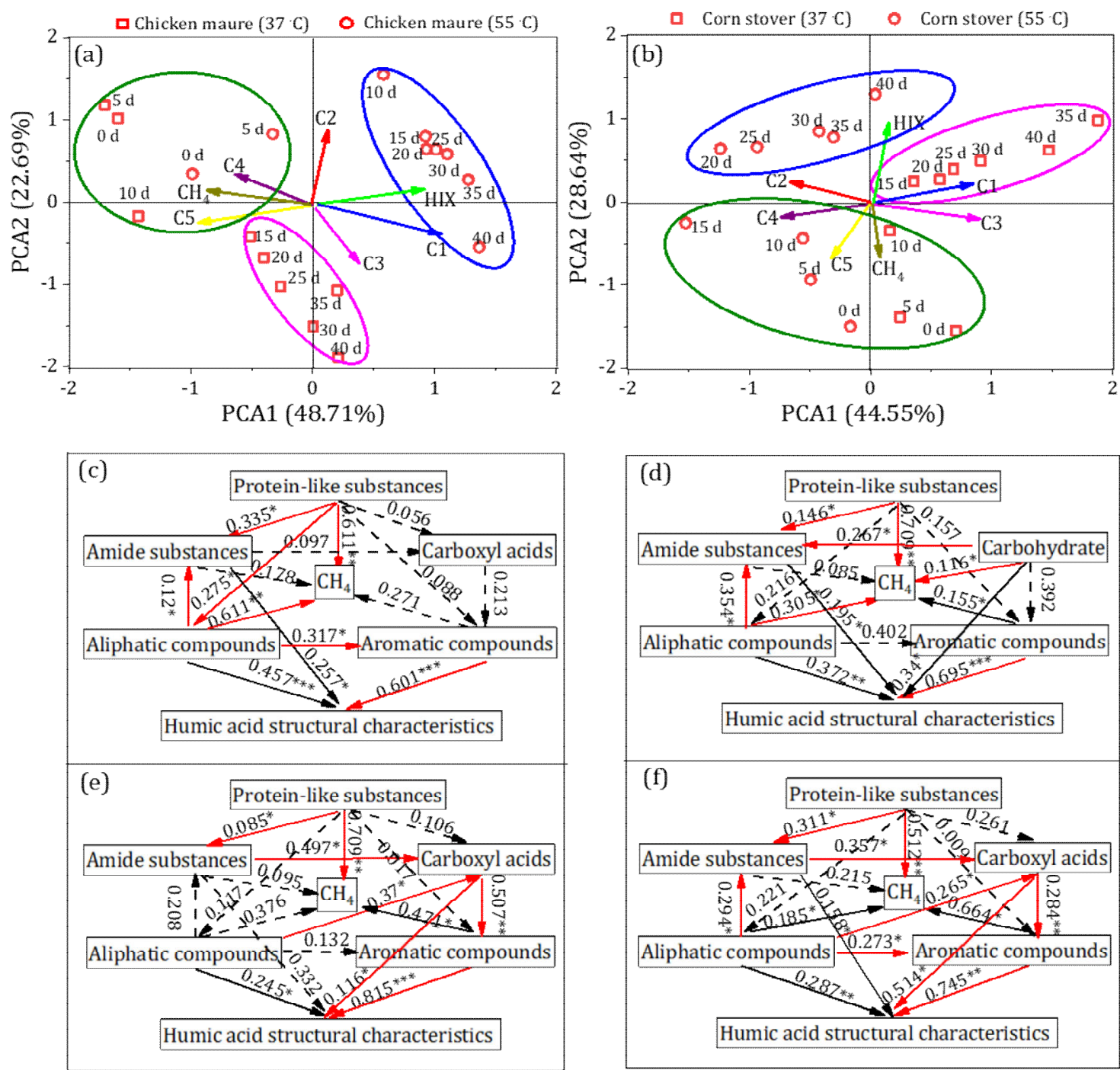

Fig. 5. Principal component analysis biplot considering the changes in organic matter during the anaerobic digestion process with (a) chicken manure and (b) corn stover at different temperatures. A structural equation model (SEM) showing the direct and indirect effects of the key factors on $\mathrm{HA}$ formation and methane production in the fast methane production stage and slow methane production stage of chicken manure (c), (e) and corn stover (d), (f) anaerobic digestion. The path coefficients are adjacent to the arrows, ${ }^{*} p<0.05 ;{ }^{* *} p<0.01 ;{ }^{* * *} p<0.001$. (HIX: humification index; C1, C3: humic acid-like substance; C2: Fulvic acid-like substance; C4: Tyrosine-like substance; $\mathrm{C5}$ : Tryptophan-like substance)

To evaluate the possible transformation and decomposition pathways of HA during the

$A D$ process, the species and quantities of HA compositions were assessed in both the fast and slow $\mathrm{CH}_{4}$ production stages using Py-GC/MS (Fig. S6). The main compositions of the HA from the AD of chicken manure and corn stover were slightly different; however, 
they can be generally categorized into aldehydes, alcohols, amines, acids, ketones, benzenes, phenols, and hydrocarbons (Table S8 and S9). Based on the aforementioned information, the potential mechanism of $H A$ transformation during the $A D$ process is summarized in Fig. 6. In the chicken manure AD process (Fig. 6a), the initial basic structural units of $\mathrm{HA}$, which are composed of a variety of easily degradable substances (such as aliphatic compounds, amides, and protein), were first degraded to contribute to $\mathrm{CH}_{4}$ production in the fast $\mathrm{CH}_{4}$ production stage (Tang et al., 2018; Gao et al., 2019). Then, the small molecules, such as those with carboxyl-rich groups of aromatic compounds and amide compounds, attached to these basic units of HA by condensation reactions and finally formed more complex and humified structures (Sánchez-Monedero et al., 1999; Baddi et al., 2009; Said-Pullicino et al., 2016). However, the formation of HA in the corn stover $A D$ process showed different pathways (Fig. 6b). First, the intermediates from carbohydrate and polyphenol compound degradation are rich in carboxyl and hydroxyl moieties and serve as the precursor of HA to form low-molecularweight compounds with HA characteristics, such as amides. These compounds react with aromatic-like substances to form a tight polymer that is also regarded as the "core" of HA. Then, in a process similar to the chicken manure AD process, easily degradable compounds (such as aliphatic and polysaccharides) were decomposed. As the fermentation continues, some small-molecule organic acids (e.g., carboxyl), as the intermediates between amide and aliphatic compound degradation, attach to the surface of the core of HA, forming more mature and stable HA macromolecules (Jiang et al., 2015; Wu et al., 2017; Gao et al., 2019). 
$479 \mathrm{CH}_{4}$ production was also significantly affected by the dynamic electron transferring 480 ability of the formed $\mathrm{HA}$, along with their structural evolution during the AD process (Fig. 481 S7). In the fast $\mathrm{CH}_{4}$ production stage, the positive effect of $\mathrm{HA}$ on $\mathrm{CH}_{4}$ production may 482 not only be sacrificing aliphatic compounds, amides, and carbohydrates in HA as carbon 483 resources, but may also be facilitating the electron transfer chain among various 484 microbially mediated reactions, such as acidogenesis, acetogenesis, and 485 methanogenesis (Fernandes et al., 2015; Li et al., 2019a). In the following slow $\mathrm{CH}_{4}$ production stage, however, the functional groups in more humified HA can bind to the preventing their access to substrates and resulting in lower $\mathrm{CH}_{4}$ generation (Yap et al., 2017). The result also provides evidence that the highly humified HA with high ETC has the potential to serve as terminal electron acceptors during microbial respiration and to 491 function as electron shuttles driving the anaerobic oxidation of methane (AOM, Bai et 492 al., 2019). Note that the microbial community and abundance that perform the HAdependent AOM process were not involved in this study; therefore, the direct relationship between the HA formed by the AD process and the AOM process, functional microbes, and electron transfer mechanisms needs to be further analyzed.

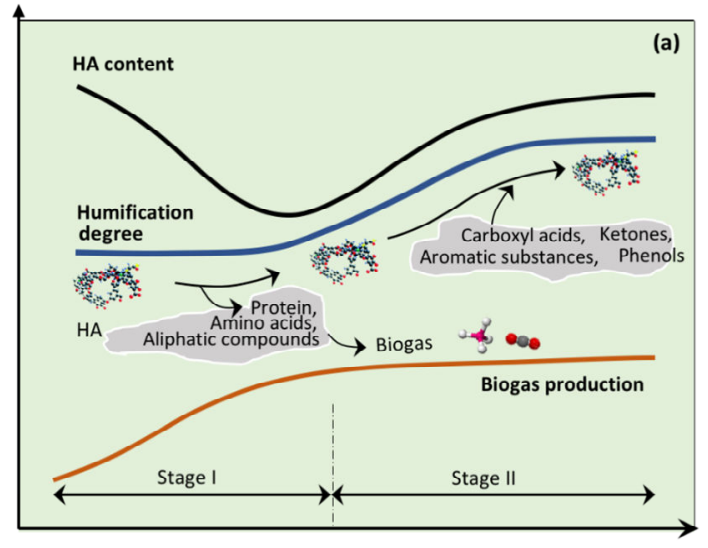

Chicken Manure Batch Anaerobic Digestion Process

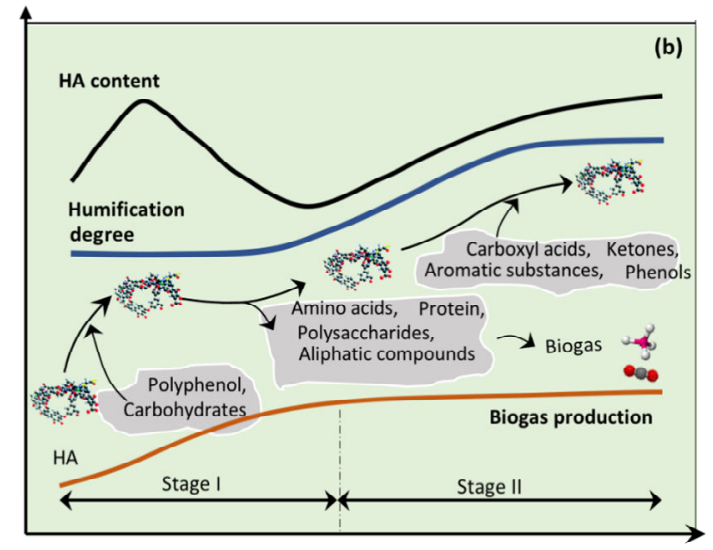

Corn Stover Batch Anaerobic Digestion Process 
Fig. 6. The possible transformation and decomposition pathways of humic acid during anaerobic digestion with (a) chicken manure and (b) corn stover.

\subsection{Significance of this work}

The existence of HA formed in the AD system could create a negative effect on the energy efficiency of the conversion of waste $\mathrm{OM}$ to $\mathrm{CH}_{4}$ (Bai et al., 2019; Li et al., 2019b); however, this conclusion was based on previous studies with the external addition of commercial HA, which can hardly reflect the impact of genuine HA that naturally formed in the AD process with a dynamic structure and function. Our research conducted in-situ monitoring of the dynamics of HA evolution, including degradation, formation, structure variation, functional groups, and ETC alternation to re-evaluate the interaction effect. The present study proved that the decomposition of aliphatic, amide, carbohydrate, and protein-like compounds in $\mathrm{HA}$ positively correlated with $\mathrm{CH}_{4}$ production in the fast $\mathrm{CH}_{4}$ production stage, and the accumulation of the re-polymerized HA in the later stage negatively correlated with $\mathrm{CH}_{4}$ production in the $\mathrm{AD}$ process. Moreover, the impact of $H A$ on $A D$ performance is significantly dependent on the humification degree or aromaticity of $\mathrm{HA}$, which varies with fermentation time and temperature. The thermophilic conditions significantly promoted the evolution of the HA structure during the AD process. The formation mechanisms of HA were also different in the AD of different feeding materials, i.e., chicken manure and corn stover. Further studies could investigate the microbial community characterisation in relation to the $\mathrm{HA}$ transformation. Nevertheless, with the current results, this study improves our understanding of the transformation of $\mathrm{HA}$ itself and its dynamic effects on other carbon metabolism pathways and thus improves the transparency of the knowledge "black box" that exists in the $A D$ process. 
521 From the perspective of engineering applications, this study may provide an evidence-

522 based recommendation for optimising the operations of AD process in order to improve

523 the $\mathrm{CH}_{4}$ production efficiency. The current applied AD plants are normally operated

524 under a hydraulic retention time of 20-30 days for manures (Li et al., 2020) and 40-50

525 days for lignocellulosic biomass (Guo et al., 2018; Xu et al., 2020), respectively.

526 Considering the potential interactive effect of genuine HA formed in the AD process on

$527 \mathrm{CH}_{4}$ production, the current findings may suggest a shorter retention time. However, to 528 consolidate this conclusion, further research is still needed..

\section{4. Conclusions}

530 This study investigated the evolutionary dynamics of the structure and function of 531 genuine HA that naturally formed in the AD processes and re-evaluated its dynamic 532 interaction with $\mathrm{CH}_{4}$ production. The concurrent decomposition and re-polymerization 533 of HA during the AD process was observed, however, the HA evolution mechanisms in 534 the AD of chicken manure and corn stover showed different pathways. An accelerating 535 effect of the higher temperature on the evolution of HA through humification was also 536 confirmed from the results of HSQC NMR spectroscopy and 2D-COS-FTIR spectroscopy 537 detections. The HA performed positive and negative effects on $\mathrm{CH}_{4}$ production in the 538 fast and slow $\mathrm{CH}_{4}$ production stages, respectively. The dynamic interaction was due to 539 variations in the electron transferring ability and structure of the formed HA. The results 540 could support further research and deployment of $A D$ toward improving $A D$ 541 performance by regulating the evolution of the HA.

\section{Acknowledgments}


543 This work was financed by the AIAS-COFUND fellowship Programme, which is funded by

544 the European Union's Seventh Framework Programme for Research, Technological

545 Development and Demonstration under grant agreement no. 609033.

\section{Appendix A. Supplementary data}

547 Supplementary data associated with this article can be found in the Supporting 548 Information. Text S1-S2, additional analytical methods; Figures S1-S7, daily methane 549 production, the relative proportion of fluorescence components, 2D-COS HSQC NMR 550 spectra, FTIR spectra, ETC, Py-GC/MS spectra, and the relationship between ETC and daily methane production; Table S1-S9, characteristics of physicochemical properties of

the AD process, EEM spectra PARAFAC analysis, the percent aliphaticity and aromaticity of HA, elemental composition, SUVA values, and typical products by Py-GC/MS analysis.

\section{References}

Appels, L., Baeyens, J., Degreve, J., Dewil, R., 2008. Principles and potential of the anaerobic digestion of waste-activated sludge. Prog. Energ. Combus. 34, 755-781. APHA (American, Public Health Association), AWWA (American Water Works and Protection Association) and WPCF (Water Pollution Control Federation), 1998. Standard Methods for the Examination of Water and Wastewater 20td ed., Washington, D.C.

Bahram, M., Bro, R., Stedmon, C., Afkhami, A., 2006. Handing of Rayleigh and Raman scatter for PARAFAC modeling of fluorescence data using interpolation. J. Chemom. 20, 99-105.

Bai, Y. N., Wang, X. N., Wu, J., Lu, Y. Z., Fu, L., Zhang, F., Lau, T. C., Zeng, R. J., 2019. Humic substances as electron acceptors for anaerobic oxidation of methane driven by ANME-2d. Water Res. 164, 114935.

Baddi, G.A., Cegarra, J., Merlina, G., Revel, J.C., Hafidi, M., 2009. Qualitative and quantitative evolution of polyphenolic compounds during composting of an olivemill waste-wheat straw mixture. J. Hazard. Mater. 165, 1119-1123.

Croce, S., Qiao, W., D'Imporzano, G., Dong, R., Adani, F., 2016. Anaerobic digestion of straw and corn stover: The effect of biological process optimization and pre- 
treatment on total bio-methane yield and energy performance. Biotech. Advan. 34, 1280-1304.

Fernandes, T. V., van Lier, J. B., Zeeman, G., 2015. Humic acid-like and fulvic acid-like inhibition on the hydrolysis of cellulose and tributyrin. BioEnergy Res. 8 (2), 821831.

Grace, J. B., 2006. Structural Equation Modeling and Natural Systems; Cambridge University Press.

Gao, X., Tan, W., Zhao, Y., Wu, J., Sun, Q., Qi, H., Xie, X., Wei, Z., 2019. Diversity in the mechanisms of humin formation during composting with different materials. Environ. Sci. Technol. 53, 3653-3662.

Guo, X. X., Liu, H. T., Wu, S. B., 2019. Humic substances developed during organic waste composting: Formation mechanisms, structural properties, and agronomic functions. Sci. Total Environ. 662, 501-510.

Guo, J., Cui, X., Sun, H., Zhao, Q., Wen, X., Pang, C., Dong, R., 2018. Effect of glucose and cellulase addition on wet-storage of excessively wilted maize stover and biogas production, Bioresour. Technol. 259, 198-206.

He, X. S., Xi, B. D., Gao, R. T., Wang, L., Ma, Y., Cui, D. Y., Tan, W. B., 2015. Using fluorescence spectroscopy coupled with chemometric analysis to investigate the origin, composition, and dynamics of dissolved organic matter in leachate-polluted groundwater. Environ. Sci. Pollut. Res. 22, 8499-8506.

Hayes, M. H. B., 2009. Evolution of concepts of environmental natural nonliving organic matter; Wiley interscience: New York, NY.

He, S., Ding, L. L., Li, K., Hu, D. H., Ye, L., Ren, H. Q., 2018. Comparative study of activated sludge with different individual nitrogen compositions, metagenomic and microbial community. Bioresour. Technol. 247, 915-923.

Huguest, A., Vacher, L., Relexans, S., Saubusse, S., Froidefond, J. M., Parlanti, E., 2009. Properties of fluorescent dissolved organic matter in the Gironde Estuary. Org. Geochem. 40(6), 706-719.

He, X. S., Xi, B. D., Cui, D. Y., Liu, Y., Tan, W. B., Pan, H. W., Li, D., 2014. Influence of chemical and structural evolution of dissolved organic matter on electron transfer capacity during composting. J. Hazad. Mat. 268, 256-263.

Hardie, A. G., Dynes, J. J., Kozak, L. M., Huang, P. M., 2009. The role of glucose in abiotic humification pathways as catalyzed by birnessite. J. Mol. Catal. A Chem. 308, 114126.

Lopez, M. J., Elorrieta, M. A., Vargas-Garcia, M. C., Suarez-Estrella, F., Moreno, J., 2002. The effect of aeration on the biotransformation of lignocellulosic wastes by whiterot fungi. Bioresour. Technol. 81, 123-129. 
Li, B., Dinkler, K., Zhao, N., Sobhi, M., Merkle, W., Liu, S., Dong, R., Oechsner, H., Guo, J., 2020. Influence of anaerobic digestion on the labile phosphorus in pig, chicken, and dairy manure. Sci. Total Environ. 737, 140234.

Li, J., Hao, X., van Loosdrecht, M. C. M., Luo, Y., Cao, D., 2019a. Effect of humic acids on batch anaerobic digestion of excess sludge. Water Res. 155, 431-443.

Li, J., Hao, X., Loosdrecht, M. C. M., Yu, J., Liu, R., 2019b. Adaptation of semi-continuous anaerobic sludge digestion to humic acids. Water Res. 161, 329-334.

Luo, H., Lyu, T., Muhmood, A., Xue, Y., Wu, H., Meers, E., Dong, R., Wu, S., 2018. Effect of flocculation pre-treatment on membrane nutrient recovery of digested chicken slurry: Mitigating suspended solids and retaining nutrients. Chem. Eng. J. 352, 855862.

Liu, Y. R., Yang, Z., Zhou, X., Qu, X., Li, Z., Zhong, H., 2019. Overlooked Role of Putative Non-Hg Methylators in Predicting Methylmercury Production in Paddy Soils. Environ. Sci. Technol. 53, 1230-12338.

Jiang, J., Liu, X., Huang, Y., Huang, H., 2015. Inoculation with nitrogen turnover bacterial agent appropriately increasing nitrogen and promoting maturity in pig manure composting. Waste Manag. 39, 78-85.

Ma, S., Hu, H., Wang, J., Liao, K., Ma, H., Ren, H., 2019. The characterization of dissolved organic matter in alkaline fermentation of sewage sludge with different $\mathrm{pH}$ for volatile fatty acids production. Water Res. 164, 114924.

Maynaud, G., Druilhe, G., Daumoin, M., Jimenez, J., Patureau, D., Torrijos, M., Pourcher, A. M., Wery, N., 2017. Characterization of the biodegradability of post-treated digestates via the chemical accessibility and complexity of organic matter. Bioresour. Technol. 231, 65-74.

Martins des Neves, L. C., Concert, A., Vessoni Penna, T. C., 2009. Biogas production: new trends for alternative energy sources in rural and urban zones. Chem. Eng. Technol. 32, 1147-1153.

Mylotte, R., Sutrisno, A., Farooq, H., Masoom, H., Soong, R., Hayes, M. H. B., Simpson, A. J., 2016. Insight into the composition of recalcitrant organic matter from estuarine sediments using NMR spectroscopy. Org. Geochem. 98, 155-165.

Noda, I., Ozaki, Y., 2004. Two-dimensional correlation spectroscopy applications in vibrational and optical spectroscopy. John Wiley, England.

Nie, X., Li, Z., Huang, J., Liu, L., Xiao, H., Liu, C., Zeng, G., 2018. Thermal stability of organic carbon in soil aggregates as affected by soil erosion and deposition. Soil Tillage Res. $175,82-90$.

Onwosi, C. O., Igbokwe, V. C., Odimba, J. N., Eke, I. E., Nwankwoala, M. O., Iroh, I. N., Ezeogu, L. I., 2017. Composting technology in waste stabilization: on the methods, challenges and future prospects. J. Environ. Manag. 190, 140-157. 
Putranto, A., Chen, X. D., 2017. A new model to predict diffusive self-heating during composting incorporating the reaction engineering approach (REA) framework. Bioresour. Technol. 232, 211-221.

Swift, R. S., Sparks, D. L., Madison, W., 1996. Isolation of IHSS soil fulvic and humic acid from http://humic-substances.org/isolation-of-ihss-soil-fulvic-and-humic-acids/. Exerpt from-organic matter characterization (chap 35). In: Method of soil analysis, pp. 1018-1020. Part 3. Chemical methods. Soil Sci. Soc. Am. Book Series: 5. Soil Sci. Soc. Am.

Said-Pullicino, D., Miniotti, E. F., Sodano, M., Bertora, C., Lerda, C., Chiaradia, E. A., Romani, M., Cesari de Maria, S., Sacco, D., Celi, L., 2016. Linking dissolved organic carbon cycling to organic carbon fluxes in rice paddies under different water management practices. Plant Soil 401, 273-290.

Somers, M. H., Azman, S., Sigurnjak, I., Ghyselbrecht, K., Meers, E., Meesschaert, B., Appels, L., 2018. Effect of digestate disintegration on anaerobic digestion of organic waste. Bioresour. Technol. 268, 568-576.

Sepehr, S. Y., Hedenstrom, M., Stehr, J. E., Dario, M., Hertkorn, N., Bjorn, A., 2018. Pretreatment of anaerobic digester samples by hydrochloric acid for solution-state $1 \mathrm{H}$ and $13 \mathrm{C}$ NMR spectroscopic characterization of organic matter. Chemosphere, 199, 201-209.

Sánchez-Monedero, M. A., Roig, A., Cegarra, J., Bernal, M. P., 1999. Relationships between water-soluble carbohydrate and phenol fractions and the humification indices of different organic wastes during composting. Bioresour. Technol. 70, 193201.

Sale, V., Aguilera, P., Laczko, E., Mader, P., Berner, A., Zihlmann, U., van der Heijden, M. G. A., Oehl, F., 2015. Impact of conservation tillage and organic farming on the diversity of arbuscular mycorrhizal fungi. Soil Biol. Biochem. 84, 38-52.

Shahbeig, H., Nosrati, M., 2020. Pyrolysis of biological wastes for bioenergy production: Thermo-kinetic studies with machine-learning method and Py-GC/MS analysis. Fuel, 269, 117238.

Tedetti, M., Cuet, P., Guigue, C., Goutx, M., 2011. Characterization of dissolved organic matter in a coral reef ecosystem subjected to anthropogenic pressures using multidimensional fluorescence spectroscopy. Sci. Total Environ. 409, 2198-2210.

Tang, Y., Li, X., Dong, B., Huang, J., Wei, Y., Dai, X., Dai, L., 2018. Effect of aromatic repolymerization of humic acid-like fraction on digestate phytotoxicity reduction during high-solid anaerobic digestion for stabilization treatment of sewage sludge. Water Res. 143, 436-444.

Tang, Y., Dai, X., Dong, B., Guo, Y., Dai, L., 2020. Humification in extracellular polymeric substances (EPS) dominates methane release and EPS reconstruction during the sludge stabilization of high-solid anaerobic digestion. Water Res. 175, 115686. 
Tan, K. H., 2014. Humic matter in soil and the environment: Principles and controversies. CRC Press.

Tan, W., Xi, B., Wang, G., Jie, J., He, X., Mao, X., Gao, R., Huang, C., Zhang, H., Li, D., Jia, Y., Yuan, Y., Zhao, X., 2017. Increased electron-accepting and decreased electron donating capacities of soil humic substances in response to increasing temperature. Environ. Sci. Technol. 51, 3176-3186.

Wu, J. O., Zhao, Y., Zhao, W., Yang, T. X., Zhang, X., Xie, X. Y., Cui, H. Y., Wei, Z. M., 2017. Effect of precursors combined with bacteria communities on the formation of humic substances during different materials composting. Bioresour. Technol. 226, 191-199.

Weishaar, J. L., Aiken, G. R., Bergamaschi, B. A., Fram, M. S., Fujii, R., Mopper, K., 2003. Evaluation of specific ultraviolet absorbance as an indicator of the chemical composition and reactivity of dissolved organic carbon. Environ. Sci. Technol. 37 (20), 4702-4708.

Wang, X., Muhmood, A., Dong, R., Wu, S., 2020. Synthesis of humic-like acid from biomass pretreatment liquor: Quantitative appraisal of electron transferring capacity and metal-binding potential. J. Clean. Prod. 255,120243.

Wang, M., Zhao, Z., Zhang, Y., 2019. Disposal of Fenton sludge with anaerobic digestion and the roles of humic acids involved in Fenton sludge, Water Res. 163, 114900.

Xu, H., Li, Y., Hua, D., Zhao, Y., Mu, H., Chen, H., Chen, G. 2020. Enhancing the anaerobic digestion of corn stover by chemical pretreatment with the black liquor from the paper industry. Bioresour. Technol. 306, 123090.

Yap, S. D., Astals, S., Lu, Y., Peces, M., Jensen, P. D., Batstone, D. J., Tait, S., 2018. Humic acid inhibition of hydrolysis and methanogenesis with different anaerobic inocula. Waste Manage. 80, 130-136.

Yap, S. D., Astals, S., Jensen, P. D., Batstone, D. J., Tait, S., 2017. Indigenous microbial capability in solid manure residues to start-up solid-phase anaerobic digesters. Waste Manage. 64, 79-87.

Yang, F., Zhang, S., Cheng, K., Antonietti, M., 2019. A hydrothermal process to turn waste biomass into artificial fulvic and humic acids for soil remediation. Sci. Total Environ. 686, 1140-1151.

Zhang, W., Wei, Q., Wu, S., Qi, D., Li, W., Zuo, Z., Dong, R., 2014. Batch anaerobic codigestion of pig manure with dewatered sewage sludge under mesophilic conditions. Appl. Energ. 128, 175-183.

Zhao, X., Tan, W., Peng, J., Dang, Q., Zhang, H., Xi, B., 2020. Biowaste-source-dependent synthetic pathways of redox functional groups within humic acids favoring pentachlorophenol dichlorination in composting process. Environ. Intern. 135, 105380. 
Zhou, Y., Selvam, A., Wong, J. W. C., 2014. Evaluation of humic substances during cocomposting of food waste, sawdust and Chinese medicinal herbal residues. Bioresour. Technol. 168, 229-234.

Zhang, Y. C., Yue, B. D., Ma, H., 2015. Darkening mechanism and kinetics of humification process in catechol-Maillard system. Chemosphere, 130, 40-45.

729 